\title{
Physalis peruviana-Derived 4 $\beta$-Hydroxywithanolide E, a Novel Antagonist of Wnt Signaling, Inhibits Colorectal Cancer In Vitro and In Vivo
}

\author{
Zhen-Nan Ye ${ }^{1,2,3,+}{ }^{\circ}$, Feng Yuan ${ }^{1,2, \dagger}$, Jie-Qing Liu ${ }^{1}$, Xing-Rong Peng ${ }^{1}$, Tao An ${ }^{1}$, Xue Li ${ }^{1,2}$, \\ Ling-Mei Kong ${ }^{1, *}$, Ming-Hua Qiu ${ }^{1, *}$ and Yan Li $^{1, *}$ \\ 1 State Key Laboratory of Phytochemistry and Plant Resources in West China, Kunming Institute of Botany, \\ Chinese Academy of Sciences, Kunming 650201, China; zhennan.ye@med.uni-jena.de (Z.-N.Y.); \\ yuanfeng@mail.kib.ac.cn (F.Y.); liujieqing@hqu.edu.cn (J.-Q.L.); pengxingrong@mail.kib.ac.cn (X.-R.P.); \\ antao@mail.kib.ac.cn (T.A.); lixue@mail.kib.ac.cn (X.L.) \\ 2 University of the Chinese Academy of Sciences, Beijing 100049, China \\ 3 Present Address: Department of Biochemistry II, Jena University Hospital, 07743 Jena, Germany \\ * Correspondence: konglingmei@mail.kib.ac.cn (L.-M.K.); mhchiu@mail.kib.ac.cn (M.-H.Q.); \\ liyanb@mail.kib.ac.cn (Y.L.); Tel.: +86-871-65212303 (L.-M.K.); \\ +86-871-65223327 (M.-H.Q.); +86-871-65223088 (Y.L.) \\ + These Authors contributed equally to this work.
}

Academic Editors: Atanas G. Atanasov, Karel Šmejkal and Elke Heiss Received: 15 February 2019; Accepted: 20 March 2019; Published: 22 March 2019

\begin{abstract}
Deregulation of the Wnt signaling pathway leads to colorectal cancer progression. Natural dietary compounds serve as promising candidates for development as chemopreventive agents by suppressing the Wnt/ $\beta$-catenin signaling pathway. Physalis peruviana-derived $4 \beta \mathrm{HWE}$ showed a significant inhibitory activity with a calculated $\mathrm{IC}_{50}$ of $0.09 \mu \mathrm{M}$ in a screening of novel inhibitors of Wnt signaling with the dual-luciferase reporter assay. This study investigated the anti-tumor effect of $4 \beta \mathrm{HWE}$ and the potential Wnt signaling inhibitory mechanism. Both the western blot analysis and immunofluorescence assay showed that $4 \beta \mathrm{HWE}$ promoted the phosphorylation and degradation of $\beta$-catenin and the subsequent inhibition of its nuclear translocation to attenuate the endogenous Wnt target gene expression in colorectal cancer (CRC) cells. The cell viability assay indicated that $4 \beta \mathrm{HWE}$ preferentially inhibited the proliferation of CRC compared with CCD-841-CoN, a normal human colonic epithelial cell line. $4 \beta \mathrm{HWE}$-mediated G0/G1 cell cycle arrest and apoptosis induction contributed to the suppression of the proliferation of CRC in the cell cycle and Annexin V-FITC/ Propidium Iodide apoptosis analysis. Moreover, in vivo, $4 \beta \mathrm{HWE}$ dramatically inhibited tumor growth in HCT116 xenografts by attenuating the Wnt/ $\beta$-catenin signaling pathway. In conclusion, our study suggested that $4 \beta \mathrm{HWE}$ could be of potential use in anti-tumor agent development as a novel Wnt signaling inhibitor.
\end{abstract}

Keywords: $4 \beta \mathrm{HWE}$; Wnt signaling pathway; $\beta$-catenin; colorectal cancer

\section{Introduction}

The highly evolutionarily conserved $\mathrm{Wnt} / \beta$-catenin signaling pathway is integral in embryonic development, the regeneration of tissues in adult organisms, stem cell differentiation, and tissue homeostasis, as well as many other biological processes [1]. Wnts are secreted glycoproteins that trigger a great amount of cellular responses upon activation. The core of the Wnt signaling pathway is the degradation of the transcription co-factor $\beta$-catenin mediated by the destruction complex, consisting of Axin, casein kinase 1 (CK1), glycogen synthase kinase-3 $\beta$ (GSK-3 $\beta$ ), and adenomatous polyposis coli (APC). In the absence of Wnt ligands, the destruction complex mediates the phosphorylation of 
$\beta$-catenin sequentially by CK1 and GSK-3 $\beta$ and targets $\beta$-catenin for ubiquitination and continuous proteasome-mediated degradation to keep the low $\beta$-catenin level in the cytoplasm. Once bound by Wnt, the degradation pathway is inhibited, and the phosphorylation and degradation of $\beta$-catenin is suppressed. The accumulation of $\beta$-catenin leads to its nuclear translocation and complex formation with the transcription factors, T-cell factor (TCF)/Lymphoid enhancer-binding factor (LEF), in the nucleus to regulate the expression of proteins required for cell proliferation and survival, such as cyclin D1, c-Myc, and the anti-apoptotic protein survivin [2-4].

The Wnt/ $\beta$-catenin signaling pathway is critically involved in the initiation and progression of various cancers, especially colorectal cancers (CRCs), due to the mutation of APC, Axin, and the CTNNB1 gene encoding $\beta$-catenin $[5,6]$. Subsequent overexpression of the Wnt downstream target genes that function in cell growth (cyclin D1 and c-Myc) and epithelial-mesenchymal transition (EMT) (E-cadherin and matrix metalloproteases) further promote the malignancy of tumor growth and metastasis [7]. Wnt/ $\beta$-catenin signaling has become a novel and promising therapeutic target in cancer treatment, and the manipulation of the Wnt/ $\beta$-catenin signaling pathway has been suggested as a valid treatment option for CRC.

Recently, naturally derived compounds represent an attractive class of compounds for chemopreventive agent development. Several natural dietary compounds have been suggested as promising alternative options for their ability to inhibit cancers by suppressing the Wnt/ $\beta$-catenin signaling pathway, such as Genistein, Epigallocatechin gallate, Curcumin, and Resveratrol [8]. Physalis peruviana (golden berry) is an edible plant used as a diuretic and treated for malaria, asthma, hepatitis, dermatitis, and rheumatism in folk medicine $[9,10]$. Physalis peruviana-derived $4 \beta$-Hydroxywithanolide $\mathrm{E}(4 \beta \mathrm{HWE})$ is a natural withanolide with a $17 \alpha$-oriented side chain [11,12], exhibiting anti-inflammatory effects in diabetic mouse adipose tissue [13] by attenuating NF- $\mathrm{KB}$ signaling and obvious anti-tumor activity against various cancer cells [14-19]. Further mechanism studies suggested that $4 \beta$ HWE-induced cytostatic activity was associated with DNA damage [17-19], the generation of reactive oxygen species (ROS) [18], apoptosis [17,18], and cell cycle arrest [17]. Despite the promising anti-tumor actions of $4 \beta \mathrm{HWE}$, the detailed mechanisms of these biological effects remain generally unknown in colorectal cancers.

In this study, we explored the effect of $4 \beta \mathrm{HWE}$ on Wnt signaling and the growth of CRC cells. Our results suggested that $4 \beta \mathrm{HWE}$ might be a potential inhibitor of Wnt signaling and could be developed as a chemopreventive agent for CRCs.

\section{Results}

\section{1. $4 \beta H W E$ is A Potent Inhibitor of the Wnt/ $\beta$-Catenin Pathway}

To identify novel antagonists of the Wnt/ $\beta$-catenin pathway, a cell-based screening strategy of 4000 compounds from the natural product and natural product-like library (information available from the Big Data Center for Natural Products, State Key Laboratory of Phytochemistry and Plant Resources in West China, Kunming Institute of Botany) was conducted using the dual-luciferase reporter assay in HEK293 cells stably transfected with SuperTopflash luciferase (ST-Luc), Wnt3a, and Renilla [20]. The screening yielded several hits, among which $4 \beta \mathrm{HWE}$ exhibited a strong inhibitory activity in the initial screening and re-screening and was subjected to further study, with $\mathrm{IC}_{50}$ of $0.09 \pm 0.006 \mu \mathrm{M}$ (Figure 1). The structure-activity relationship analysis suggests that the basic structural requirement for the Wnt signaling inhibitory activity of $4 \beta \mathrm{HWE}$ is the $\alpha, \beta$-unsaturated cyclohexenone at $\mathrm{C}-1$, $\mathrm{C}-2$, and $\mathrm{C}-3$ and a hydroxyl group at C-4 in A ring, as well as 5,6-epoxyl group in B ring. Thus, the hydrogenation of the conjugated fraction and/or A ring shrinkage, as in K1A1, K2D1, K2S1, and K2S2, lead to a decrease of their Wnt inhibitory activities. In addition, the reduction of 5,6-epoxyl results in lower inhibition activities, as in K2D1, K2S1, KJQ1, K2S2, K1D1, and K1S3. Additionally, three free hydroxyl groups at C-14, C-17, and C-20 also play an important role in inhibiting the growth of tumor cells. Compared to K2D3, K2D2, and K2S4, any substitution, reduction, and cyclization could 
affect their inhibitory activities. Moreover, when an $\alpha, \beta$-unsaturated $\delta$-lactone in the side chain is converted to the $\gamma$-lactone, as in KJQ1, K1D1, and K1S3, the Wnt signaling inhibitory activities of these compounds decrease significantly.

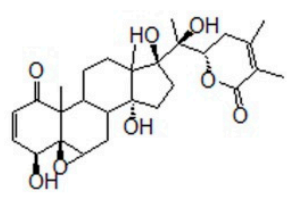

4ßHWE $0.09 \pm 0.006 \mu \mathrm{M}$

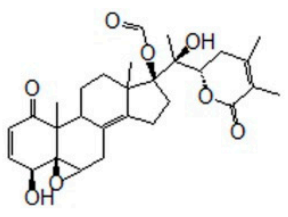

K2S3 $0.11 \pm 0.002 \mu \mathrm{M}$

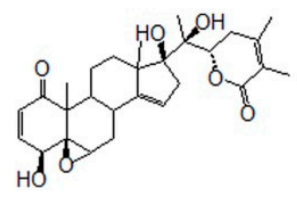

K2D2 $0.86 \pm 0.07 \mu \mathrm{M}$

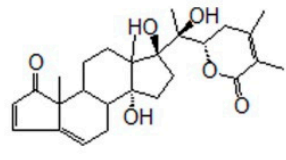

$\mathrm{K} 2 \mathrm{D} 13.37 \pm 0.07 \mu \mathrm{M}$

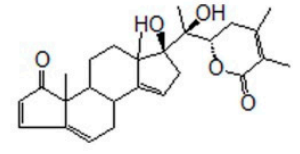

$\mathrm{K} 2 \mathrm{~S} 13.83 \pm 0.84 \mu \mathrm{M}$

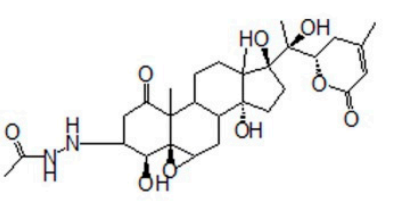

$\mathrm{K} 1 \mathrm{~A} 115.14 \pm 1.76 \mu \mathrm{M}$

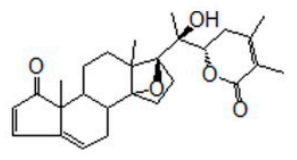

K2S2 $29.98 \pm 0.85 \mu \mathrm{M}$

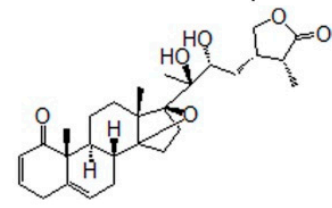

$\mathrm{K} 1 \mathrm{D} 1>40 \mu \mathrm{M}$

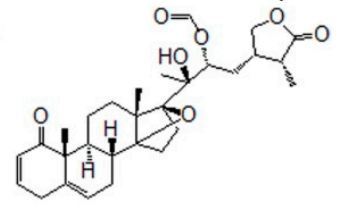

$\mathrm{K} 1 \mathrm{~S} 3>40 \mu \mathrm{M}$

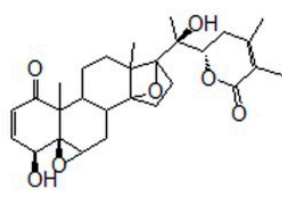

K2S4 $1.14 \pm 0.08 \mu \mathrm{M}$

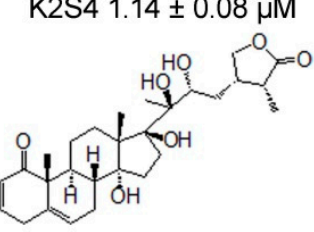

KJQ1 $26.68 \pm 2.23 \mu \mathrm{M}$

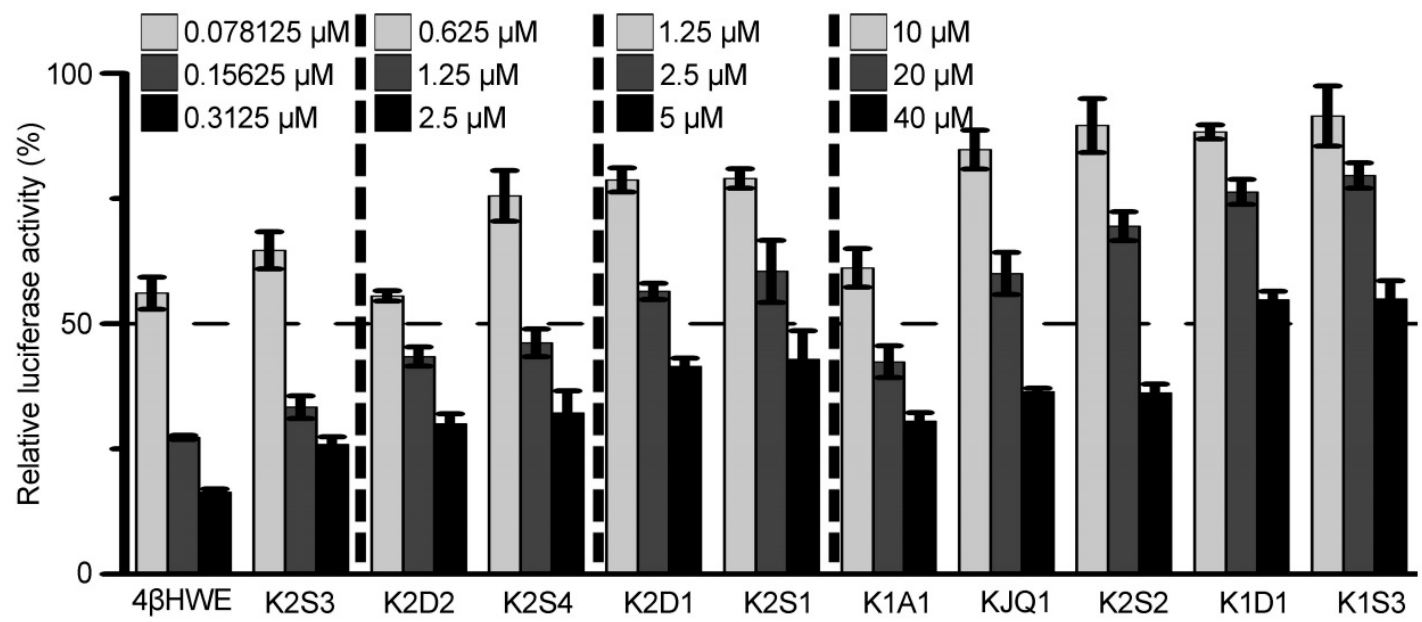

Figure 1. Identification and structure-activity relationship of $4 \beta \mathrm{HWE}$ as a novel Wnt signaling antagonist. HEK293 cells stably transfected with SuperTopflash luciferase (ST-Luc), Wnt3a, and Renilla cells were incubated with $4 \beta \mathrm{HWE}$ or its analogs for $24 \mathrm{~h}$. The inhibitory activity of the compounds was analyzed. The values represent the mean $\pm \mathrm{SD}(n=3)$. The half ST-Luc inhibition $\left(\mathrm{IC}_{50}\right)$ values were calculated, and the data represent the mean \pm SD from three independent experiments.

\section{2. $4 \beta H W E$ Interferes with the Wnt Signaling in Colorectal Cancer Cells}

Deregulation of the Wnt signaling pathway contributed to tumorigenesis of human CRC; the inhibitory activity of $4 \beta \mathrm{HWE}$ on the Wnt signaling in CRC was studied with the dual-luciferase reporter assay. As shown in Figure 2A, the Wnt signaling activity was strikingly attenuated in HCT116 and SW480 cells, and the calculated $\mathrm{IC}_{50}$ values were $1.85 \pm 0.45 \mu \mathrm{M}$ and $2.67 \pm 0.11 \mu \mathrm{M}$ in HCT116 and SW480 cells, respectively. Further western blotting results showed that the endogenous Wnt responder gene expression of cyclin D1, c-Myc, and Axin2 was suppressed in HT29, HCT116, and SW480 colorectal cancer cells treated with $4 \beta \mathrm{HWE}$ (Figure 2B). The above results further confirmed $4 \beta \mathrm{HWE}$ as an inhibitor of Wnt signaling and deserving of further investigation. 


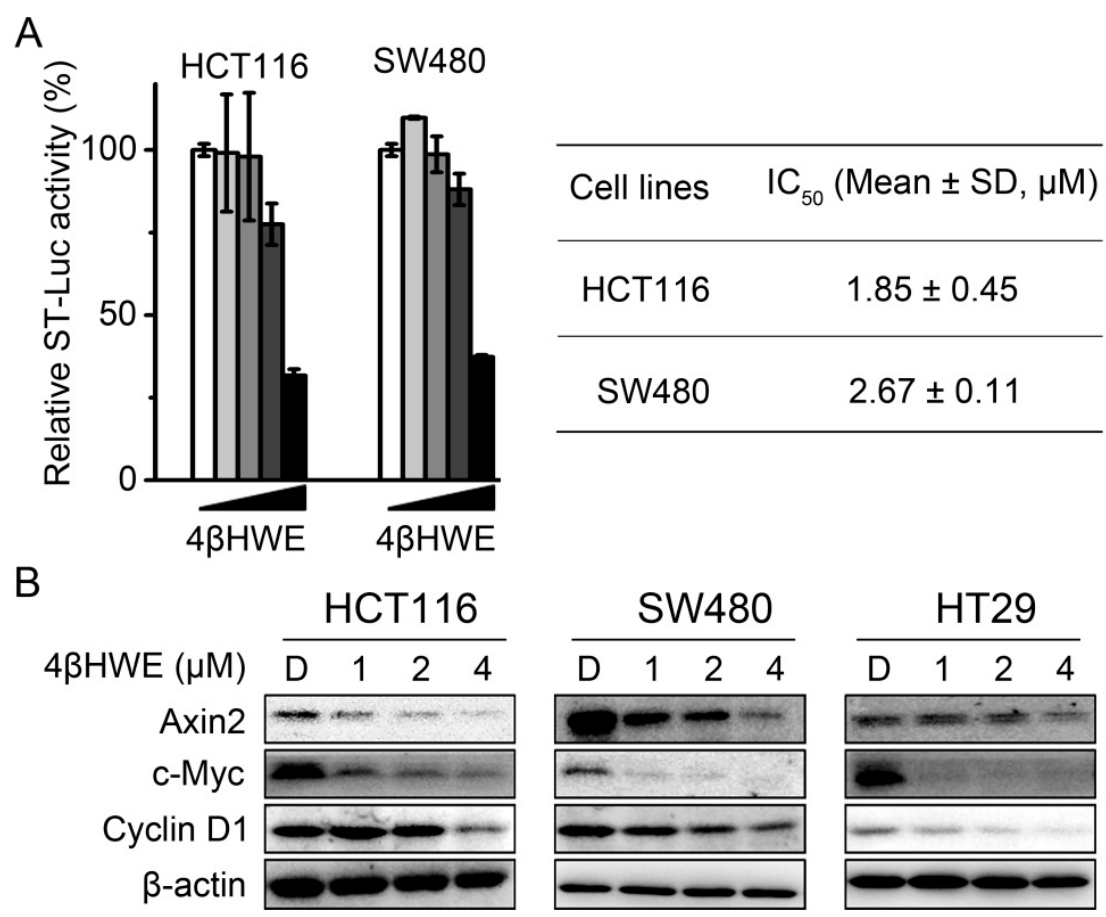

Figure 2. $4 \beta \mathrm{HWE}$ suppresses the endogenous Wnt signaling pathway in colorectal cancer (CRC). (A) HCT116 and SW480 cells were treated with $0.0064,0.032,0.16,0.8$ and $4 \mu \mathrm{M}$ of $4 \beta \mathrm{HWE}$ for $24 \mathrm{~h}$, and the Wnt signaling inhibitory activity of $4 \beta \mathrm{HWE}$ was measured with the dual-luciferase reporter assay. The values represent the mean $\pm \mathrm{SD}(n=3)$. (B) Western blot analysis of lysates from HCT116, SW480, and HT29 cells treated with DMSO (D), 1, 2 and $4 \mu \mathrm{M} 4 \beta \mathrm{HWE}$ for $24 \mathrm{~h}$.

\section{3. $4 \beta H W E$ Inhibits the Stability and Nuclear Translocation of $\beta$-Catenin in CRC}

The activity of the Wnt / $\beta$-catenin signaling pathway is largely dependent on the level of $\beta$-catenin, the core molecule in the pathway [21], the stability of which is regulated by the phosphorylation and degradation of $\beta$-catenin by the proteasome [22]. Thus, to investigate the underlying mechanism that $4 \beta \mathrm{HWE}$ inhibits in Wnt signaling, we detected the effect of $4 \beta \mathrm{HWE}$ on the expression and phosphorylation levels of $\beta$-catenin. HEK293 cells stably transfected with Wnt3a were treated with $4 \beta \mathrm{HWE}$ for $24 \mathrm{~h}$, and the cell lysates were subjected to western blot analysis. A significant increase in the phosphorylation of $\beta$-catenin on Ser33/37/Thr41 residues and the reduction of the total level of $\beta$-catenin were observed (Figure 3A). Consistently, HCT116 cells incubated with $4 \beta \mathrm{HWE}$ with incremental time and concentration led to an increase of phospho- $\beta$-catenin and a decrease in both the active nonphosphorylated form and the total $\beta$-catenin (Figure 3B,C) in western blot analysis. As the destructive complex consisted of GSK3 $\beta$ /Axin/APC/CK1, the cytoplasmic $\beta$-catenin level was maintained at a low level [1]. GSK3 $\beta$ functions as a negative regulator of the Wnt signaling pathway through controlling the phosphorylation and degradation of $\beta$-catenin [23]. The decreased expressions of the inactive status GSK3 $\beta$ (Ser9) and the accumulation of the total level of GSK3 $\beta$ protein in HCT116 cells were observed in cells treated with $4 \beta \mathrm{HWE}$ (Figure 3B,C).

Accumulation of phosphorylated $\beta$-catenin led to the subsequent nuclear translocation inhibition of $\beta$-catenin. The immunofluorescence assay was carried out to analyze the distribution of $\beta$-catenin. As shown in Figure 3D, as an inhibitor of GSK-3 $\beta$ [24], LiCl induced the nuclear translocation of $\beta$-catenin, while the endogenous nuclear translocation of $\beta$-catenin in HCT116 cells was suppressed by $4 \beta$ HWE. Consistently, the level of $\beta$-catenin in the cytoplasmic and the nucleic fraction of HCT116 cells was attenuated when treated with $4 \beta \mathrm{HWE}$ in the western blotting assay (Figure $3 \mathrm{E}$ ).

To further investigate the role of the $\beta$-catenin/TCF transcription pathway in $4 \beta \mathrm{HWE}$-mediated anti-tumor activity, the proliferation inhibitory activity of $4 \beta \mathrm{HWE}$ in SW480 cells, with $\beta$-catenin knocked down using small interfering RNA, was detected. As shown in Figure 3F, the siRNA-mediated 
knock-down of $\beta$-catenin reduced the sensitivity of cells to $4 \beta \mathrm{HWE}$, further confirming that $\beta$-catenin/TCF is required for the anti-tumor activity of $4 \beta \mathrm{HWE}$, in part at least.

A

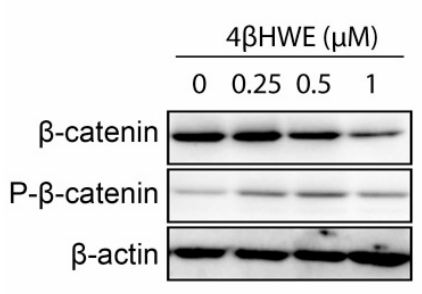
B $\frac{\text { Time }(\mathrm{h})}{4 \mathrm{HWE}} \frac{8}{-+\frac{8}{-+}+\frac{16}{-+}}$
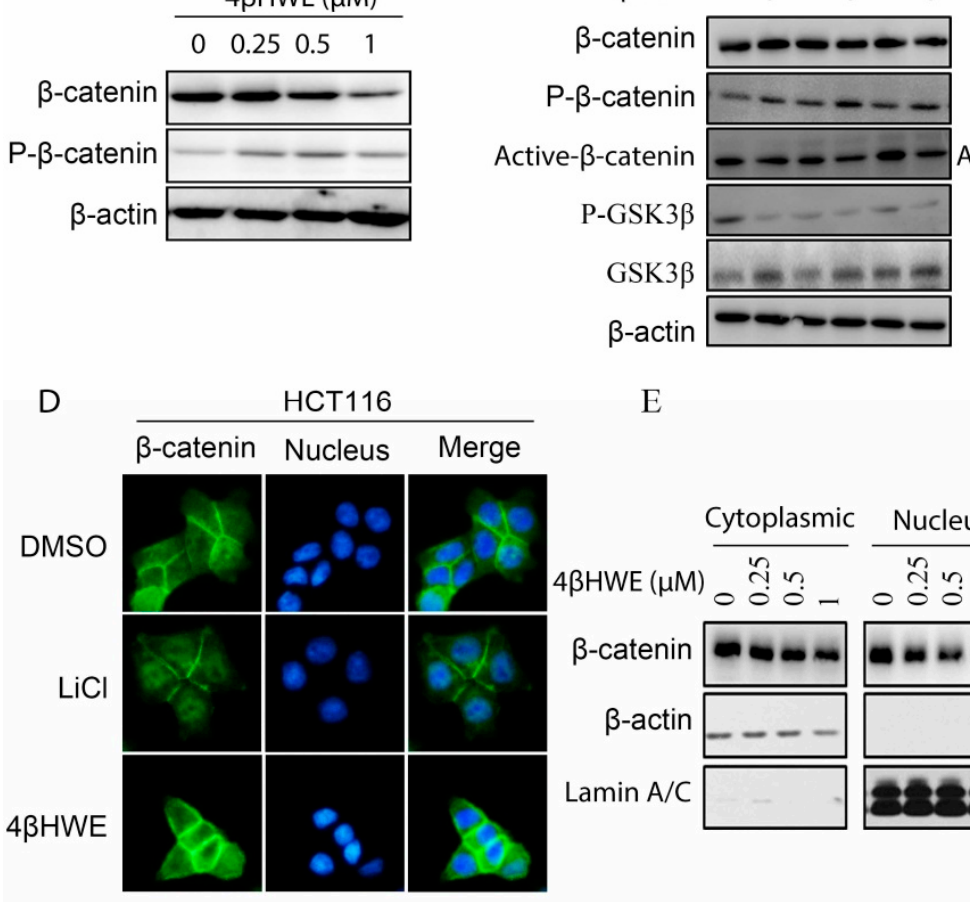

$\mathrm{E}$

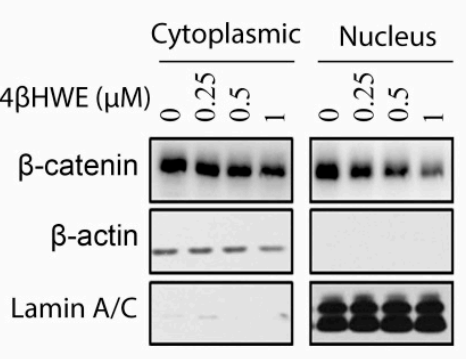

$$
\text { C }
$$
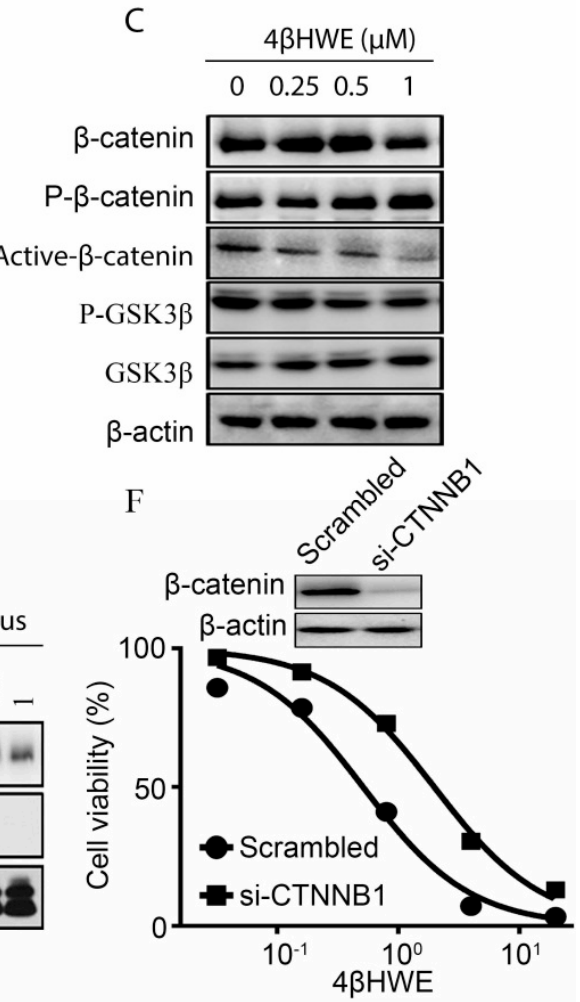

Figure 3. $4 \beta \mathrm{HWE}$ disrupts the stability and nuclear translocation of $\beta$-catenin in colorectal cancer cells. (A) HEK293 cells stably transfected with Wnt3a were treated with $4 \beta \mathrm{HWE}$ for $24 \mathrm{~h}$; $\beta$-catenin and p- $\beta$-catenin (Ser33, Ser37, and Thr41) were detected with western blot analysis. (B) HCT116 cells were treated with $1 \mu \mathrm{M}$ of $4 \beta \mathrm{HWE}$ for $4 \mathrm{~h}, 8 \mathrm{~h}$, and $16 \mathrm{~h}$ or indicated concentrations of $4 \beta \mathrm{HWE}$ for $16 \mathrm{~h}$ respectively $(\mathrm{C})$, and western blot analysis of $\beta$-catenin, $\mathrm{p}$ - $\beta$-catenin (Ser33, Ser37, and Thr41), active- $\beta$-catenin, p-GSK3 $\beta$ (Ser9), and total GSK3 $\beta$ was performed. (D) HCT116 cells were incubated with or without $4 \beta \mathrm{HWE}(1 \mu \mathrm{M})$. The $\beta$-catenin distribution was detected with the immunofluorescence assay. The green and blue fluorescence represent $\beta$-catenin and the nucleus, respectively. (E) HCT116 cells were incubated with $0,0.25,0.5$, and $1 \mu \mathrm{M}$ of $4 \beta \mathrm{HWE}$ for $16 \mathrm{~h}$. The levels of cytoplasmic fraction and nucleic fraction $\beta$-catenin in the $4 \beta \mathrm{HWE}$-treated HCT116 cell lysates were analyzed by western blot. (F) The SW480 cells were transfected with CTNNB1 small interfering RNA for $36 \mathrm{~h}$, and the proliferation inhibitory activity of $4 \beta \mathrm{HWE}$ was measured with the cell viability assay. The knock-down efficiency was analyzed by western blot.

\section{4. $4 \beta H W E$ Selectively Suppresses the Proliferation of CRC}

The proliferation inhibition effects of $4 \beta \mathrm{HWE}$ on CRC were evaluated with MTS assays in four cancer cells, including HCT116, SW480, HT29, and LoVo, as well as CCD-841-CoN (a normal human

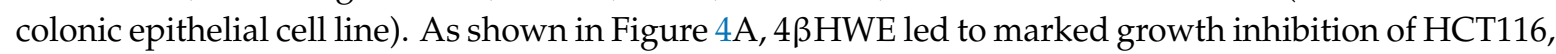
SW480, HT29, and LoVo, and the $\mathrm{IC}_{50}$ values were $0.43 \pm 0.03 \mu \mathrm{M}, 0.52 \pm 0.03 \mu \mathrm{M}, 0.49 \pm 0.05 \mu \mathrm{M}$, and $0.29 \pm 0.01 \mu \mathrm{M}$, respectively (Figure 4B). Notably, $4 \beta \mathrm{HWE}$ exhibited lower toxicity to normal colonic epithelial cells (CCD-841-CoN) (the green line in Figure 4A) in comparison with CRC cells, with a calculated $\mathrm{IC}_{50}$ value of $1.24 \pm 0.09 \mu \mathrm{M}$, suggesting that $4 \beta \mathrm{HWE}$ selectively exhibited growth inhibition on CRC. 


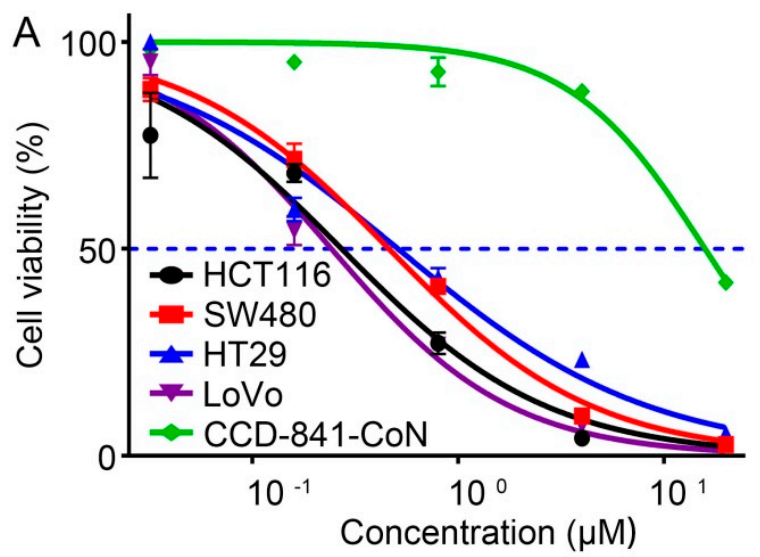

B

Figure 4. 4 $\beta \mathrm{HWE}$ selectively suppresses the proliferation of CRC. (A) The proliferation inhibition of $4 \beta \mathrm{HWE}$ on CRCs, including four colorectal cancer cell lines (HCT116, SW480, HT29, and LoVo) and CCD-CoN-841, a normal human colonic epithelial cell line, was determined by MTS assay. Cells were treated with $4 \beta \mathrm{HWE}$ for up to $48 \mathrm{~h}$. (B) The median inhibition concentration $\left(\mathrm{IC}_{50}, 48 \mathrm{~h}\right.$ ) values of $4 \beta \mathrm{HWE}$ for various cell lines were calculated.

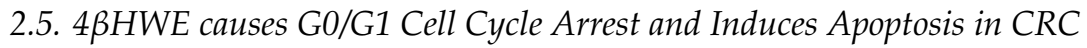

To explore the mechanism of $4 \beta \mathrm{HWE}$ suppressing the proliferation of CRC, cell cycle distribution and cell apoptosis induced by $4 \beta \mathrm{HWE}$ were investigated with the propidium iodide (PI) and Annexin V-FITC/PI double staining respectively. As shown in Figure 5A, 4 $3 \mathrm{HWE}$ caused G0/G1 cycle arrest in HCT116 and HT29 cells. The percentages of G0/G1 cells in HCT116 and HT29 cells were $40.04 \%$ and $49.93 \%$ in cells treated with DMSO, and the numbers run up to $81.04 \%$ and $89.99 \%$ with $1 \mu \mathrm{M}$ $4 \beta \mathrm{HWE}$ treated for $24 \mathrm{~h}$, respectively. In the apoptosis assay, as shown in Figure $5 \mathrm{~B}$, the percentage of apoptotic cells drastically went up in a dose-dependent manner in 4ßHWE-treated HCT116 and SW480 cells. The proportions of apoptotic cells in HCT116 and SW480 cells were $5.77 \%$ and $2.56 \%$, respectively, which dramatically increased to $73.93 \%$ and $77.00 \%$ in $1 \mu \mathrm{M} 4 \beta \mathrm{HWE}$ when incubated for $48 \mathrm{~h}$. We further confirmed that proteolytic cleavages of caspase 3, caspase 8, and PARP-1 were involved in 4 $\beta$ HWE-induced apoptosis in HCT116 and SW480 cells with the western blotting assay (Figure 5C,D). 
A
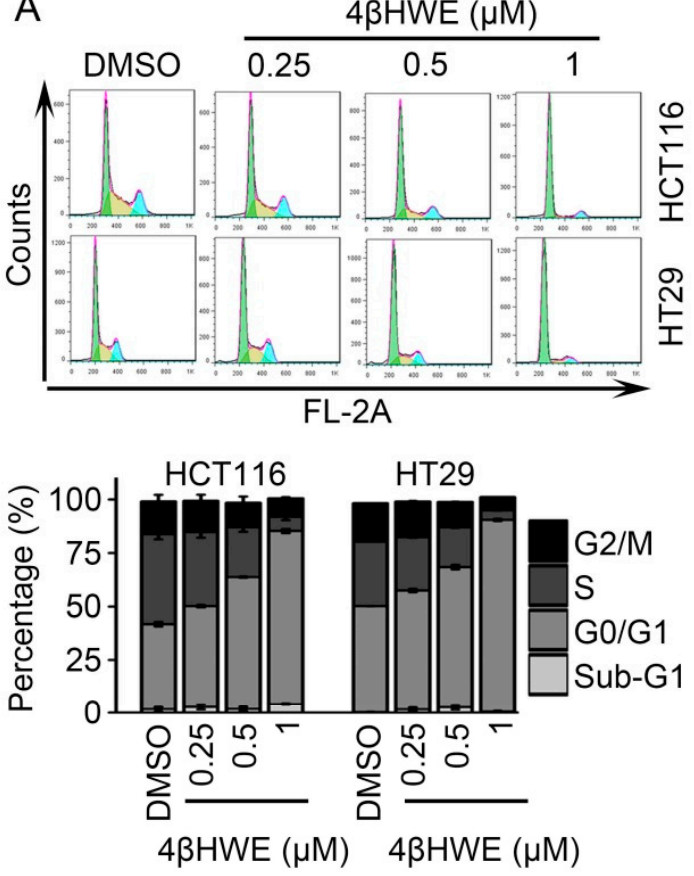

C

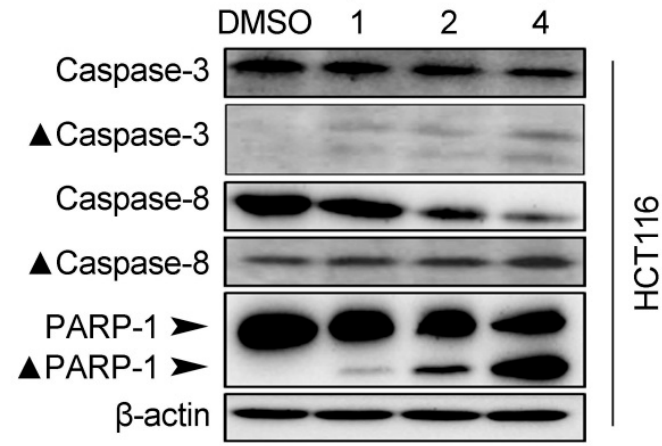

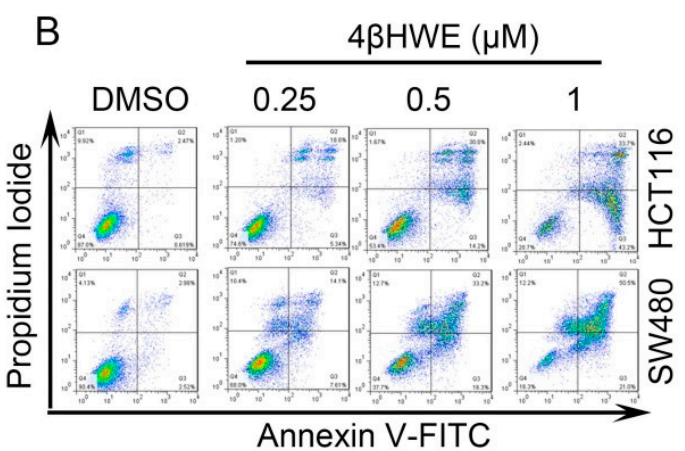

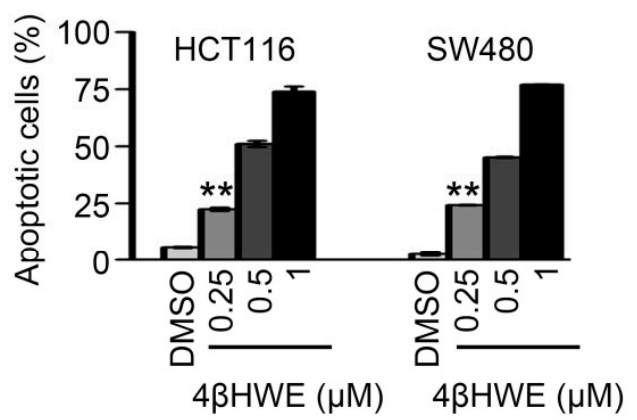

$\mathrm{D}$

$$
\text { 4ßHWE }(\mu \mathrm{M})
$$

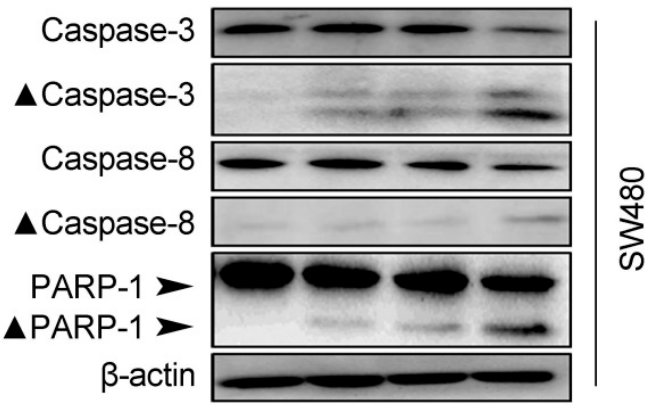

Figure 5. 4 $\beta \mathrm{HWE}$ induced G0/G1 cycle arrest and apoptosis in CRC. (A) HCT116 and HT29 cells were treated with indicated concentrations of $4 \beta \mathrm{HWE}$ for $24 \mathrm{~h}$ respectively, and the distribution of the cell cycle was documented. (B) Cells were treated with $4 \beta \mathrm{HWE}$ for $48 \mathrm{~h}$, stained with Annexin V-FITC and PI, and analyzed by flow cytometry. $P$-values were derived from the Student's t-test ${ }^{*} p<0.05$, ** $p<0.01$ ). HCT116 (C) and SW480 cells (D) were treated with DMSO, 1, 2, and $4 \mu \mathrm{M}$ of $4 \beta \mathrm{HWE}$ for $24 \mathrm{~h}$, and the lysates were subjected to western blot analysis. The level of apoptosis-related proteins was detected.

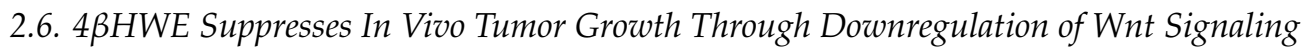

The tumor inhibitory activity of $4 \beta \mathrm{HWE}$ was further evaluated in vivo using a BALB/c-nude mouse HCT116 cell xenograft model. Briefly, $4 \times 10^{6}$ HCT116 cells were implanted subcutaneously to the right flank of the mice to develop murine xenograft models. Five days later, the HCT116 xenografts borne by the BALB/c mice were randomly assigned into a control and an experimental group. The mice were treated daily with normal saline as controls or with $5 \mathrm{mg} / \mathrm{kg}$ and $10 \mathrm{mg} / \mathrm{kg}$ of $4 \beta H W E$ by intraperitoneal injection.

As shown in Figure 6A, a daily intraperitoneal administration of $4 \beta \mathrm{HWE}$ at the dose of $5 \mathrm{mg} / \mathrm{kg}$ hardly changed the tumor volume due to the quick tumor growth, while $10 \mathrm{mg} / \mathrm{kg}$ of $4 \beta \mathrm{HWE}$ dominantly attenuated the growth of the human colon cancer HCT116 xenograft with slight body weight loss, as compared to the control group (Figure 6B). We then sacrificed the animals and excised 
the tumors on the 14 th day for weight measurement and subsequent western blot analysis. The tumors of mice treated with $10 \mathrm{mg} / \mathrm{kg} 4 \beta \mathrm{HWE}$ were approximately $809 \mathrm{~mm}^{3}$, while the tumors in the control group grew to approximately $1347 \mathrm{~mm}^{3}$, and a dominant reduction in tumor weight was observed (Figure 6C). Further western blot analysis results showed that the expressions of the Wnt target genes Axin2, c-Myc, survivin, and cyclin D1 were significantly downregulated in the tumor tissues treated with $4 \beta$ HWE (Figure 6D), with a slight decrease of $\beta$-catenin and an increase of Ser33/Ser37/Thr41 phosphorylation of $\beta$-catenin. Collectively, these data indicated that $4 \beta \mathrm{HWE}$ inhibited in vivo Wnt signaling in HCT116 xenograft tumors, consistent with our in vitro data.

A

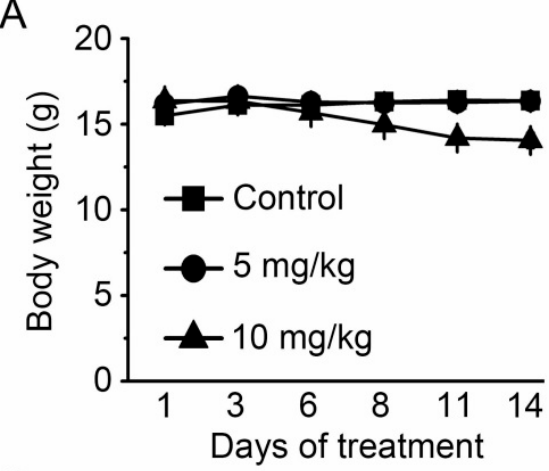

C
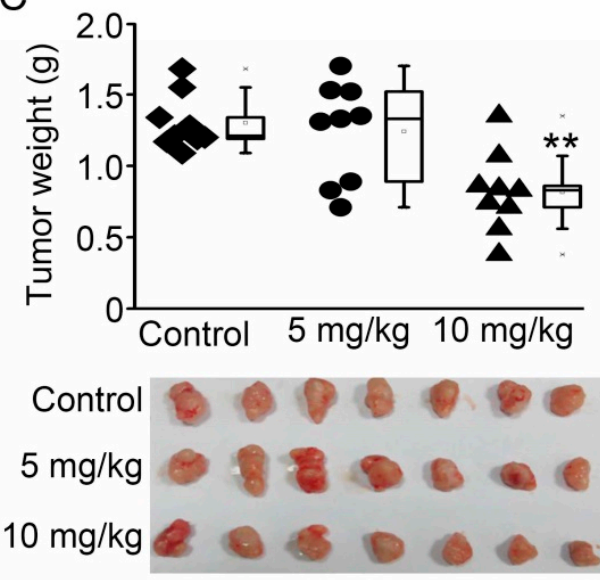

B

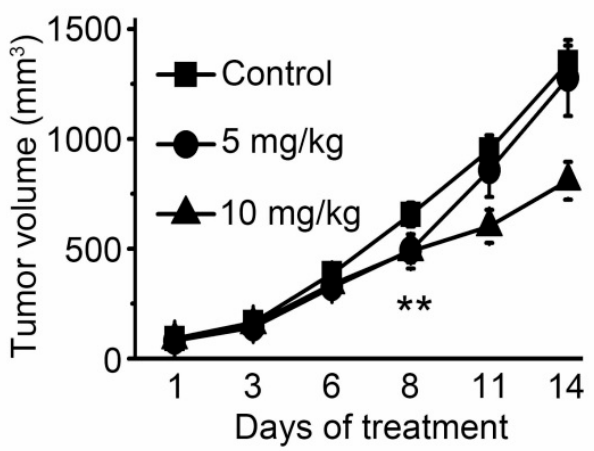

D

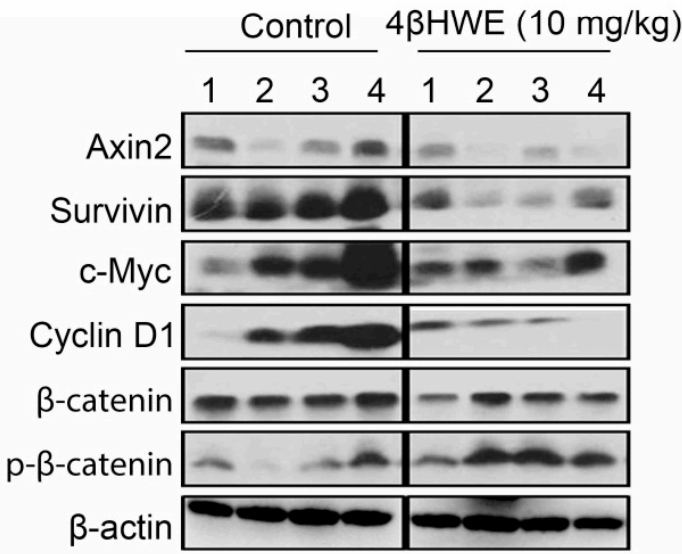

Figure 6. $4 \beta \mathrm{HWE}$ inhibits tumor growth of in vivo HCT116 xenograft through Wnt signaling. (A) $4 \times 10^{6}$ HCT116 cells were injected into BALB/c-nude mice, and normal saline was given as a control or $4 \beta \mathrm{HWE}$ was injected at a dose of $5 \mathrm{mg} / \mathrm{kg}$ and $10 \mathrm{mg} / \mathrm{kg} /$ day for 14 days. The body weight was measured as the treatment started. (B) The individual HCT116 xenograft tumor volume was monitored. (C) The weight of each tumor was measured on the 14th day, and the average tumor weight was calculated. The representative external appearance of the tumors are shown upon normal saline or $4 \beta \mathrm{HWE}$ treatments. (D) The effect of $4 \beta \mathrm{HWE}$ on the expression of Wnt-related proteins in tumor tissues was determined by western blot analysis.

\section{Discussion}

There is convincing evidence that deregulation of Wnt/ $\beta$-catenin signaling contributes to the progression of colorectal cancers [25]. In this study, we found that $4 \beta \mathrm{HWE}$ was a potential dietary chemopreventive agent against HEK293 cells with overexpressed Wnt3a, and $\alpha, \beta$-unsaturated ketone of $\mathrm{A}$ ring and $\beta-\mathrm{OH}$ at $\gamma$ position were demonstrated to be the main functional groups in a further structure-activity relationship analysis. Based on our results, $4 \beta \mathrm{HWE}$ treatment suppressed the $\beta$-catenin/TCF transcriptional activity and the Wnt downstream target gene expression of cyclin D1, c-Myc, and Axin 2 in CRC. Our mechanism study elucidated that $4 \beta$ HWE increased $\beta$-catenin phosphorylation and disrupted the stability of $\beta$-catenin and its subsequent nuclear translocation. 
Further studies on the $\beta$-catenin destruction complex were performed to investigate the mechanism of $4 \beta \mathrm{HWE}$. $4 \beta \mathrm{HWE}$ effectively inhibited the phosphorylation of GSK3 $\beta$ (Ser9), leading to an accumulation and activation of GSK3 $\beta$ and subsequent degradation of $\beta$-catenin and its nuclear translocation inhibition. The involvement and association of GSK3 $\beta$ in the regulation of Wnt signaling makes it an attractive therapeutic target in the development of Wnt antagonists [26], such as $\beta$-carboline alkaloid compound 9-hydroxycanthin-6-one, inhibiting Wnt signaling by activating GSK3 $\beta$ [27].

Suppression of the Wnt signaling pathway can contribute to the inhibition of cell growth of colorectal cancer cells $[28,29]$. In conclusion, $4 \beta \mathrm{HWE}$ selectively exhibited a growth inhibitory effect on CRC cells compared with CCD-841-CoN, a normal human colonic epithelial cell line. 4ßHWE-induced G0/G1 cell cycle arrest and caspases-mediated apoptosis led to in vitro inhibition of the CRC cell proliferation. Of note, $4 \beta \mathrm{HWE}$ treatment suppressed the expression of the c-Myc, Axin2, cyclin D1, and survivin Wnt target genes in the tumor tissues, as well as the induction of Ser33/Ser37/Thr41 phosphorylation of $\beta$-catenin, indicating that $4 \beta \mathrm{HWE}$ inhibits Wnt signaling in vivo to attenuate tumor proliferation.

Collectively, our results indicate that $4 \beta$ HWE effectively suppressed the CRC growth in vitro and in vivo, at least in part, by blocking Wnt/ $\beta$-catenin signaling, and that it can be of potential use in anti-tumor agent development as a novel Wnt signaling inhibitor.

\section{Materials and Methods}

\subsection{Cell Culture}

All cell lines (HCT116, SW480, and HT-29), if not otherwise declared, were obtained from the Shanghai Institute of Biochemistry and Cell Biology, Chinese Academy of Sciences (Shanghai, China). The CCD-841-CoN normal human colonic epithelial cell line was a kind gift from Dr. Li (SIBS-CAS, Shanghai, China). Cells were maintained in medium according to the manufacturers' instructions, supplemented with 10\% $(v / v)$ fetal bovine serum (HyClone), and penicillin/streptomycin (HyClone), in a humidified atmosphere with $5 \% \mathrm{CO}_{2}$ at $37{ }^{\circ} \mathrm{C}$. HEK-293W cells were cultured like the other mentioned cells but with the addition of $100 \mu \mathrm{g} / \mathrm{mL}$ G418 and $100 \mu \mathrm{g} / \mathrm{mL}$ Hygromycin B, as previously described [20].

\subsection{Cell Transfection and Luciferase Reporter Assay}

The dual-luciferase reporter assay was performed in two batches, one was in stably transfected HEK-293 cells stably transfected with SuperTopflash luciferase (ST-Luc), Wnt3a, and Renilla, and the other was with transient transfection using Lipofectamine ${ }^{\mathrm{TM}} 2000$ (Invitrogen). Regarding the latter one, HCT116 and SW480 cells were seeded in a 96-well plate and grown to approximately $70 \%$ confluence, respectively. Next, $80 \mathrm{ng} /$ well SuperTopflash (referred to as ST-Luc, kindly provided by Dr. Mao, KIZ-CAS, Kunming, China), a luciferase promoter construct containing TCF binding elements, was co-transfected with $8 \mathrm{ng}$ /well Renilla control plasmid (pRL-SV40, Promega). After $3 \mathrm{~h}$ of transfection, the cells were exposed to a series of indicated concentrations of $4 \beta \mathrm{HWE}$ for another $24 \mathrm{~h}$. Cells were then lysed and subjected to luciferase activity determination using the Dual-Luciferase Reporter Assay kit (Promega, Madison, WI, USA) following the manufacturer's protocol.

\subsection{Western Blotting Assay}

For analysis of the whole cell lysate, SDS-PAGE buffer $(62.5 \mathrm{mM}$ Tris- $\mathrm{HCl} \mathrm{pH} 6.8,10 \%$ glycerol, $2 \%$ SDS, $50 \mathrm{mM}$ DTT, and $0.01 \%$ bromophenol blue) was utilized to lyse cells after treatment. The subsequent SDS-PAGE and western blotting were carried out according to standard procedures [30]. Immunodetection was conducted using the following antibodies: anti-Survivin, anti-c-Myc, anti-Cyclin D1, anti-Axin 2, anti-PARP-1, anti-caspase 3, anti-cleaved caspase 3, anti-caspase 8 (Santa Cruz, CA, USA), anti- $\beta$-catenin (BD Biosciences), anti-phospho- $\beta$-catenin (Cell signaling Technology), anti-non-phospho (Active) $\beta$-catenin (Ser33/Ser37/Thr41) (Cell signaling 
Technology), anti-Lamin A/C (Epitomics), and anti- $\beta$-actin (Santa Cruz, CA, USA). Subsequently, the corresponding horseradish peroxidase (HRP)-conjugated secondary antibodies were used and protein bands were finally detected with LASmini 4000 (GE Healthcare, Barrington, IL, USA).

\subsection{Nuclear and Cytoplasmic Fractionation}

The collected cells were resuspended in ice-cold lysis buffer A (10 mM HEPES, $10 \mathrm{mM} \mathrm{KCl}, 1.5 \mathrm{mM}$ $\mathrm{MgCl} 2,0.5 \mathrm{mM}$ DTT, $0.4 \% \mathrm{NP}-40, \mathrm{pH} 7.9$ ) with addition of an Ethylenediaminetetraacetic acid-free protease inhibitor cocktail (Roche). After $10 \mathrm{~min}$ of incubation on ice, the lysate was centrifuged for $5 \mathrm{~min}$, at $800 \times \mathrm{g}, 4^{\circ} \mathrm{C}$. The supernatant was collected as cytoplasmic fractionation. Pellets were washed 3 times with buffer A by 5 min of incubation, gentle pipetting, and spinning at $150 \times g$ for $2 \mathrm{~min}$. The pelleted nuclei were resuspended in lysis buffer B (20 mM HEPES, pH 7.9, $420 \mathrm{mM} \mathrm{NaCl}, 0.5 \mathrm{mM}$ DTT, $0.2 \mathrm{mM}$ EDTA, and $25 \%$ glycerol) and incubated for $30 \mathrm{~min}$ on ice. Finally, the nuclear extraction was harvested after centrifugation at $12,000 \times g, 4{ }^{\circ} \mathrm{C}$.

\subsection{Small Interfering RNAs}

Duplex siRNAs were synthesized at GenePharma (Shanghai, China). The target sequences were as follows:

- Scrambled control: 5'-UUCUCCGAACGUGUCACGU-3';

- CTNNB1: 5'-AGCUGAUAUUGAUGGACAG-3'.

\subsection{Immunofluorescence Staining}

The sample preparation has been described previously [31]. Briefly, drug-treated HCT 116 cells on coverslips were fixed in freshly-prepared $4 \%$ paraformaldehyde, permeabilized with $0.1 \%$ Triton X-100, and blocked with 3\% BSA (Bovine Serum Albumin, BSA) in PBS (phosphate buffer saline, PBS). Afterwards, the cells were incubated with an anti- $\beta$-catenin antibody (BD Biosciences) overnight at $4{ }^{\circ} \mathrm{C}$. Following 3 times washing with PBS, a FITC conjugated secondary antibody (Sigma-Aldrich) was employed for $1 \mathrm{~h}$ incubation at room temperature. Ten minutes prior to the next washing step, 4',6-diamidino-2-phenylindole (DAPI) was added for nucleus staining. After washing and mounting procedures, the fluorescent images were examined under a microscope (Nikon, Tokyo, Japan).

\subsection{MTS Assay}

The MTS assay was employed to assess the cytotoxicity of the studied compounds by using CellTiter $96^{\circledR}$ AQueous One Solution Reagent (Promega). The manufacturer's protocol was followed, which is described elsewhere [32]. Briefly, $5 \times 10^{3}$ cells were seeded in a 96-well plate. After overnight settling, the indicated compounds and concentrations were added to the cells. After 48 h exposure, the CellTiter $96^{\circledR}$ AQueous One Solution Reagent was directly added and incubated with the cells for $1-4 \mathrm{~h}$, and then the optical density (OD) was recorded at $490 \mathrm{~nm}$ with a microplate reader (Bio-Rad Laboratories, Hercules, CA, USA).

\subsection{Cell Cycle Analysis}

HCT116 and HT-29 cells were exposed to indicated concentrations of $4 \beta \mathrm{HWE}$ for $24 \mathrm{~h}$, respectively. Trypsin-digested cells were then collected and fixed with $70 \%$ ethanol overnight. After 3 times washing with pre-chilled PBS, the cells were stained with $50 \mu \mathrm{g} / \mathrm{mL}$ propidium iodide (PI) solution containing $50 \mu \mathrm{g} / \mathrm{mL}$ RNase, protected from light, and incubated at room temperature for $30 \mathrm{~min}$. The samples were detected by FACSCalibur flow cytometry (BD Biosciences). The cell cycle distribution was processed by FlowJo V 7.6.1 software (Tree Star, San Carlos, CA, , USA, 2011). 


\subsection{Cell Apoptosis Analysis}

Cellular apoptosis was determined by the FITC Annexin V Apoptosis Detection Kit (BD Biosciences, San Jose, CA, USA) following the manufacturer's instructions. After $48 \mathrm{~h}$ of treatment, both adherent and suspended cells were collected and washed with cold PBS. The cell pellet was resuspended in an appropriate volume of $1 \mathrm{X}$ binding buffer to achieve a recommended cell concentration of $1 \times 10^{6}$ cells $/ \mathrm{ml}$. FITC Annexin V and PI were added, and then they were incubated at room temperature for $15 \mathrm{~min}$ while being protected from light. A calibration control was also set up. Fluorescent intensity was measured by FACSCalibur flow cytometry (BD Biosciences).

\subsection{HCT116 Colorectal Xenografts}

HCT116 cells $\left(4 \times 10^{6}\right)$ were implanted subcutaneously into the right flank of the three-week-old BALB/c-nude mice (Vita River Laboratory Animal Technology Co.), according to published methods [32]. They were housed and treated according to the guidelines of the Institutional Animal Care and Use Committee. The mice were maintained under pathogen-free conditions. Tumor growth was monitored every other day by measuring two dimensions ( $\mathrm{L}$ and $\mathrm{W}$ ) with the following calculation formula: $\mathrm{V}\left(\mathrm{mm}^{3}\right)=\left(\mathrm{L} \times \mathrm{W}^{2}\right) \times 0.5$. When tumors reached a volume of $\sim 90 \mathrm{~mm}^{3}$, the mice were randomized into two groups ( $n=9$ /group) to receive treatment. One group was treated with normal saline as a control via intraperitoneal injection, while the other group underwent $5 \mathrm{mg} / \mathrm{kg}$ and $10 \mathrm{mg} / \mathrm{kg}$ of $4 \beta \mathrm{HWE}$ treatment. Tumor size and body weight were measured three times a week for a total of 14 days. The mice were euthanized, and the tumors were harvested $6 \mathrm{~h}$ after the final $4 \beta \mathrm{HWE}$ injection. The grafts were then weighed and stored at $-80^{\circ} \mathrm{C}$ for further western blotting analysis.

Author Contributions: Z.-N.Y., F.Y., L.-M.K., and Y.L. conceived the study and designed the experimental procedures. Z.Y., F.Y., L.-M.K., T.A., and X.L. performed the experiments. J.-Q.L. and X.-R.P. extracted the compounds and performed the structure-activity relationships analysis. Z.-N.Y., F.Y., and L.-M.K. analyzed the data. L.-M.K., M.-H.Q., and Y.L. wrote this manuscript.

Funding: This research was funded by the National Natural Science Foundation of China (81773783, U1192604, 81373288, and 81603161), and the projects of the Applied Basic Research Foundation of Yunnan Province (2018FB147). The project support for L.K. from the State Key Laboratory of Phytochemistry and Plant Resources in West China, Kunming Institute of Botany, Chinese Academy of Sciences is also acknowledged.

Conflicts of Interest: The authors declare no conflict of interest.

\section{References}

1. MacDonald, B.T.; Tamai, K.; He, X. Wnt/beta-catenin signaling: Components, mechanisms, and diseases. Dev. Cell 2009, 17, 9-26. [CrossRef]

2. Nusse, R. Wnt signaling in disease and in development. Cell Res. 2005, 15, 28-32. [CrossRef]

3. Clevers, H. Wnt/beta-catenin signaling in development and disease. Cell 2006, 127, 469-480. [CrossRef] [PubMed]

4. Logan, C.Y.; Nusse, R. The Wnt signaling pathway in development and disease. Annu. Rev. Cell Dev. Biol. 2004, 20, 781-810. [CrossRef] [PubMed]

5. Klaus, A.; Birchmeier, W. Wnt signalling and its impact on development and cancer. Nat. Rev. Cancer 2008, 8 , 387-398. [CrossRef]

6. Moon, R.T.; Kohn, A.D.; De Ferrari, G.V.; Kaykas, A. WNT and beta-catenin signalling: Diseases and therapies. Nat. Rev. Genet. 2004, 5, 691-701. [CrossRef] [PubMed]

7. Oving, I.M.; Clevers, H.C. Molecular causes of colon cancer. Eur. J. Clin. Investig. 2002, 32, 448-457. [CrossRef]

8. Tarapore, R.S.; Siddiqui, I.A.; Mukhtar, H. Modulation of Wnt/beta-catenin signaling pathway by bioactive food components. Carcinogenesis 2012, 33, 483-491. [CrossRef] [PubMed]

9. Wu, S.J.; Ng, L.T.; Chen, C.H.; Lin, D.L.; Wang, S.S.; Lin, C.C. Antihepatoma activity of Physalis angulata and P. peruviana extracts and their effects on apoptosis in human Hep G2 cells. Life Sci. 2004, 74, 2061-2073. [CrossRef] [PubMed] 
10. Wu, S.J.; Ng, L.T.; Lin, D.L.; Huang, S.N.; Wang, S.S.; Lin, C.C. Physalis peruviana extract induces apoptosis in human Hep G2 cells through CD95/CD95L system and the mitochondrial signaling transduction pathway. Cancer Lett. 2004, 215, 199-208. [CrossRef] [PubMed]

11. Sakurai, K.; Ishii, H.; Kobayashi, S.; Iwao, T. Isolation of 4 beta-hydroxywithanolide E, a new withanolide from Physalis peruviana L. Chem. Pharm. Bull. 1976, 24, 1403-1405. [CrossRef] [PubMed]

12. Kirson, I.; Abraham, A.; Sethl, P.D.; Subramanlan, S.S.; Glotter, E. $4 \beta$-Hydroxywithanolide E, a new steroid with a $17 \alpha$-oriented side-chain. Phytochemistry 1976, 15, 340-342. [CrossRef]

13. Takimoto, T.; Kanbayashi, Y.; Toyoda, T.; Adachi, Y.; Furuta, C.; Suzuki, K.; Miwa, T.; Bannai, M. 4beta-Hydroxywithanolide E isolated from Physalis pruinosa calyx decreases inflammatory responses by inhibiting the NF-kappaB signaling in diabetic mouse adipose tissue. Int. J. Obes. 2014, 38, 1432-1439. [CrossRef]

14. Glotter, E. Withanolides and related ergostane-type steroids. Nat. Prod. Rep. 1991, 8, 415-440. [CrossRef]

15. Ray, A.B.; Gupta, M. Withasteroids, a growing group of naturally occurring steroidal lactones. Fortschr. Chem. Org. Nat. 1994, 63, 1-106.

16. Machin, R.P.; Veleiro, A.S.; Nicotra, V.E.; Oberti, J.C.; Padrón, J.M. Antiproliferative activity of withanolides against human breast cancer cell lines. J. Nat. Prod. 2010, 73, 966-968. [CrossRef] [PubMed]

17. Yen, C.Y.; Chiu, C.C.; Chang, F.R.; Chen, J.Y.; Hwang, C.C.; Hseu, Y.C.; Yang, H.L.; Lee, A.Y.; Tsai, M.T.; Guo, Z.L.; et al. 4beta-Hydroxywithanolide E from Physalis peruviana (golden berry) inhibits growth of human lung cancer cells through DNA damage, apoptosis and G2/M arrest. BMC Cancer 2010, 10, 46. [CrossRef] [PubMed]

18. Chiu, C.C.; Haung, J.W.; Chang, F.R.; Huang, K.J.; Huang, H.M.; Huang, H.W.; Chou, C.K.; Wu, Y.C.; Chang, H.W. Golden berry-derived 4beta-hydroxywithanolide E for selectively killing oral cancer cells by generating ROS, DNA damage, and apoptotic pathways. PLoS ONE 2013, 8, e64739. [CrossRef] [PubMed]

19. You, B.J.; Wu, Y.C.; Lee, C.L.; Lee, H.Z. Non-homologous end joining pathway is the major route of protection against 4beta-hydroxywithanolide E-induced DNA damage in MCF-7 cells. Food. Chem. Toxicol. 2014, 65, 205-212. [CrossRef]

20. Li, X.Y.; Wang, Y.Y.; Yuan, C.M.; Hao, X.J.; Li, Y. A reporter gene system for screening inhibitors of Wnt signaling pathway. Nat. Prod. Bioprospect. 2013, 3, 24-28. [CrossRef]

21. Clevers, H.; Nusse, R. Wnt/beta-catenin signaling and disease. Cell 2012, 149, 1192-1205. [CrossRef] [PubMed]

22. Hart, M.; Concordet, J.P.; Lassot, I.; Albert, I.; del los Santos, R.; Durand, H.; Perret, C.; Rubinfeld, B.; Margottin, F.; Benarous, R.; et al. The F-box protein beta-TrCP associates with phosphorylated beta-catenin and regulates its activity in the cell. Curr. Biol. 1999, 9, 207-210. [CrossRef]

23. Sadot, E.; Simcha, I.; Iwai, K.; Ciechanover, A.; Geiger, B.; Ben-Ze'ev, A. Differential interaction of plakoglobin and beta-catenin with the ubiquitin-proteasome system. Oncogene 2000, 19, 1992-2001. [CrossRef] [PubMed]

24. Kim, J.; Zhang, X.; Rieger-Christ, K.M.; Summerhayes, I.C.; Wazer, D.E.; Paulson, K.E.; Yee, A.S. Suppression of Wnt signaling by the green tea compound (-)-epigallocatechin 3-gallate (EGCG) in invasive breast cancer cells. Requirement of the transcriptional repressor HBP1. J. Biol. Chem. 2006, 281, 10865-10875. [CrossRef] [PubMed]

25. Moon, R.T.; Brown, J.D.; Torres, M. WNTs modulate cell fate and behavior during vertebrate development. Trends Genet. 1997, 13, 157-162. [CrossRef]

26. Gao, C.; Chen, G.; Romero, G.; Moschos, S.; Xu, X.; Hu, J. Induction of Gsk3beta-beta-TrCP interaction is required for late phase stabilization of beta-catenin in canonical Wnt signaling. J. Biol. Chem. 2014, 289, 7099-7108. [CrossRef]

27. Ohishi, K.; Toume, K.; Arai, M.A.; Koyano, T.; Kowithayakorn, T.; Mizoguchi, T.; Itoh, M.; Ishibashi, M. 9-Hydroxycanthin-6-one, a beta-Carboline Alkaloid from Eurycoma longifolia, Is the First Wnt Signal Inhibitor through Activation of Glycogen Synthase Kinase 3beta without Depending on Casein Kinase 1alpha. J. Nat. Prod. 2015, 78, 1139-1146. [CrossRef]

28. Anastas, J.N.; Moon, R.T. WNT signalling pathways as therapeutic targets in cancer. Nat. Rev. Cancer 2013, 13, 11-26. [CrossRef] [PubMed]

29. Baarsma, H.A.; Konigshoff, M.; Gosens, R. The WNT signaling pathway from ligand secretion to gene transcription: Molecular mechanisms and pharmacological targets. Pharmacol. Ther. 2013, 138, 66-83. [CrossRef] [PubMed] 
30. Ye, Z.N.; Yu, M.Y.; Kong, L.M.; Wang, W.H.; Yang, Y.F.; Liu, J.Q.; Qiu, M.H.; Li, Y. Biflavone Ginkgetin, a Novel Wnt Inhibitor, Suppresses the Growth of Medulloblastoma. Nat. Prod. Bioprospect. 2015, 5, 91-97. [CrossRef]

31. Dong, X.L.; Zhang, J.X.; Zhou, Z.L.; Ye, Z.N.; Chen, J.H.; Yuan, J.F.; Cao, F.J.; Wang, X.B.; Liu, W.C.; $\mathrm{Yu}$, W.X.; et al. Maslinic acid promotes autophagy by disrupting the interaction between Bcl2 and Beclin1 in rat pheochromocytoma PC12 cells. Oncotarget 2017, 8, 74527-74538. [CrossRef] [PubMed]

32. Kong, L.M.; Feng, T.; Wang, Y.Y.; Li, X.Y.; Ye, Z.N.; An, T.; Qing, C.; Luo, X.D.; Li, Y. Bisleuconothine A, a bisindole alkaloid, inhibits colorectal cancer cell in vitro and in vivo targeting Wnt signaling. Oncotarget 2016, 7, 10203-10214. [CrossRef] [PubMed]

Sample Availability: Samples of the $4 \beta H W E$ are available from the authors.

(C) 2019 by the authors. Licensee MDPI, Basel, Switzerland. This article is an open access article distributed under the terms and conditions of the Creative Commons Attribution (CC BY) license (http:/ / creativecommons.org/licenses/by/4.0/). 